\title{
CONJUGAL VIOLENCE: PRACTICES AND ATTITUDES OF GENERAL PRACTITIONER IN SFAX (TUNISIA)
}

\section{CHARFI N, DAOUD M, NAJJAR S, MAALEJ BOUALI M, OMRI S, FEKI R, ZOUARI L, BEN THABET J, MAALEJ M \\ Department of Psychiatry "C", Hedi Chaker University Hospital, Sfax, Tunisia}

\section{Background and aims:}

$\checkmark$ General practitioners (GP) are the major professional group to whom women experiencing conjugal violence turn. Working with those victims can be difficult work for GP.

$\checkmark$ The aim of this study was to analyze the practices and attitudes of GP regarding conjugal violence against women.

\section{Materials and Methods:}

$\checkmark$ It was a cross-sectional study involving $110 \mathrm{GP}$ in Sfax

$\checkmark$ Multi-topic questionnaire covering clinician knowledge, beliefs and practices on domestic violence cases, barriers and facilitators in inquiry and referral was used in interviewing clinician. It was sent to them by e-mail.

$\checkmark$ The e-mail informed them of study's purpose and invited them to answer the questionnaire in the link.

\section{Results:}

$\checkmark 52.7 \%$ of doctors interviewed were female and working for over 15 years

$\checkmark$ On average, doctors were likely to be seeing 2.8 women each year who have experienced domestic violence.

$\checkmark$ The GP working as clinicians for over 15 years in their current practice were more likely to support the victims after identifying domestic violence cases by writing a medical certificate.

\section{Discussion:}

$\checkmark$ The most identified conjugal violence in this study was the physical one. These result was similar to that found in the national survey conducted by the National Office of family and Population on violence against women in Tunisia (1). In this survey, psychological and physical violence were the most common.

$\checkmark$ Our study showed that $55 \%$ of women victims of conjugal violence were referred to a psychiatrist, $50 \%$ to the external agencies and $42 \%$ to an association specialized in the fight against conjugal violence. This result demonstrates the awareness of the doctors of the importance of a multidisciplinary support including the psychological, the social and the legal aspects. However, the referral to a support association was third. It showed the lack of knowledge of the resources and organizations offering support . Yet, providing education about the list of those resources can be additionally helpful in raising awareness.

$\checkmark$ The medical certificate describes the general state of the victim, the injuries and the physical lesions. Writing a medical certificate is an important step along the path of a woman experiencing conjugal violence. Proper documentation is important as it may be of value if the patient decides to seek legal support.

$\checkmark$ The barriers to screening for conjugal violence:

- Attitude of denial or concealment : To overcome this reluctance, the physician should ask directly about conjugal violence.

- Fear persists about these questions offending patients. GP reported barriers such as shame and fear of losing their professional relationship with the patient

- Lack of training: physicians have lack of confidence in their abilities regarding conjugal violence. History of training made physicians more likely to screen and to provide advices to women

\section{Conclusion:}

$\checkmark$ The negative social representation of conjugal violence and the lack of training in this regard seem to be the more important barriers for the detection of conjugal violence by the general practitioners.

$\checkmark$ Those factors should be taken into account when planning educational programs on this issue.

\section{Figure 1: Kinds of conjugal violence}

$55 \%$

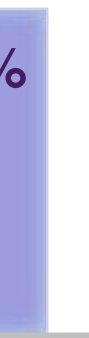

Physical violence

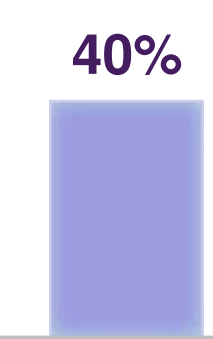

Verbal violence Sexual violence

Financia violence

Figure 2: Referrals of women victims of conjugal violence by GP

$55 \%$

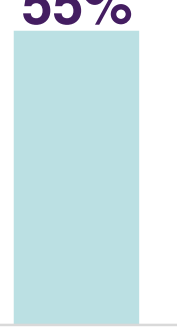

Psychiatry department

\begin{abstract}
$50 \%$
\end{abstract}
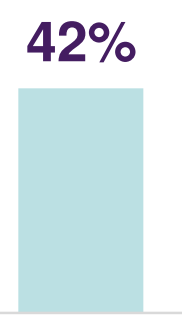

External agencies
Support association
Table I : Barriers for conjugal violence screening by GP

\begin{tabular}{lcc}
\hline & $\mathbf{N}$ & $\%$ \\
\hline Fear to intrude & 31 & $28.2 \%$ \\
Lack of clinical experience & 26 & $23.6 \%$ \\
$\begin{array}{l}\text { Rejection of any support from the } \\
\text { woman }\end{array}$ & 17 & $15.5 \%$ \\
Shame and taboo related to this issue & 14 & $13 \%$ \\
\hline
\end{tabular}

Table II: Initial management of women victims of conjugal violence

$33 \%$

Documentation of findings

$\mathbf{N}(\%)$

Provide counseling $45(40.9 \%)$

Prescription of drugs (analgesic, hypnotic, anxiolytic)

$40(36.4 \%)$

Assessment of psychological distress
$33(30 \%)$

$16(14.5 \%)$ 